\title{
Pathological Findings in Patients with Malignant Tumor: Study in the Medical University, Dhaka, Bangladesh
}

Farhad Mahmud $^{1 *}$, Shahnaz Parvin ${ }^{2}$, Farzana Rahman ${ }^{3}$, Mridul Kumar Saha $^{4}$

${ }^{1}$ Assistant Professor, Department of Pathology, Colonel Malek Medical College, Manikganj, Bangladesh

${ }^{2}$ Assistant professor, Department of Pathology, Shaheed Suhrawardy Medical College, Sher E Bangla Nagar, Dhaka, Bangladesh

${ }^{3}$ Assistant Professor, Department of Pathology, National Institute of Traumatology and Orthopedic Rehabilitation, Dhaka, Bangladesh

${ }^{4}$ Assistant Professor(CC), Department of Pathology, Colonel Malek Medical College, Manikganj, Bangladesh

DOI: $10.36347 /$ sjams.2020.v08i06.031

| Received: 02.06.2020 | Accepted: 22.06.2020 | Published: 27.06.2020

*Corresponding author: Dr. Farhad Mahmud

Abstract

Original Research Article

Introduction: Cancer is a major health challenge all over the world. It has devastating effect on individual, family and society. The number of cancer deaths worldwide has been considered to be about 4 million each year. An estimated 12.66 million people were diagnosed with cancer across the world in 2008, and 7.56 million people died from the disease. During the past century, cancer has emerged as the most challenging problems for public health systems in medium- and low-resource countries. Aim of the study: To assess the pathological findings of the patients with malignant tumor. Material \& Methods: This is a cross sectional study conducted at the Department of Pathology, Bangabandhu Sheikh Mujib Medical University, Dhaka, Bangladesh from October 2011 to September 2012. All tumor cases diagnosed by histopathology or cytopathology in the department of Pathology, BSMMU were enrolled in this study. The materials for diagnoses were biopsy specimens, surgical resection/excised specimens, and cytology specimens. All tumor reports were stored in computer data base and would be retrieved according to need. Information was collected from the patients or close relatives of the patients. Personal identification data and tumor related information including ICD-O3 and ICD 10 were collected and recorded systematically in a data abstraction sheet. Tumor identification part was filled up by a resident doctor. All precautions were maintained to avoid multiple counts of same patient. These data were entered in to software by using Microsoft access. Basic frequency distribution and proportion of data were presented in tables, figures and diagrams. Statistical analyses of the results will be obtained by using window based computer software devised with Statistical Packages for Social Sciences (SPSS-15). Results: Among 3657 cases, 2559 were malignant (69.98\%), 1098 (30.02\%0) were benign. Among malignant tumors, 11 $(0.43 \%)$ cases were of low malignant potential, $17(0.66 \%)$ were borderline malignancy, $28(1.09 \%)$ cases included carcinoma in-situ or intraepithelial/noninvasive malignancy, $58(2.27 \%)$ were uncertain whether benign or malignant, $2034(79.48 \%)$ cases were primary malignant tumors and $404(15.79 \%)$ were secondary malignant tumors. Of the total cases, $1549(42.36 \%)$ were male and $2108(57.64 \%)$ were female. The male: female ratio was 1: 1.36. The age range was from 2 to 85 years mean $47.30 \pm 16.37$ with a range of $2-85$ years. Sarcoma $16(26.66 \%)$ was the most frequent malignant tumor in pediatrics age group followed by nephroblastoma 8 (13.33\%). neuroblastoma $5(8.33 \%)$. 1482 (38\%) biopsy cases, 857 (24.3\%) resected specimens, 1281 (36.0\%) FNAC cases, 34 (1.0\%) cytology samples of body fluid cases and $3(0.1 \%)$ Scrapping /brushing cases. In male, oral cavity and oropharynx cancer top the list 159 (18\%), followed by the stomach $83(10 \%)$, liver $63(7.0 \%)$, colon and rectum $59(7 \%)$ urinary bladder $56(6.0 \%)$, thyroid 57 (7.0\%), lymph node $21(2 \%)$, kidney $33(4.0 \%)$, peri-ampullary carcinoma $45(5.0 \%)$ and oesophagus 19 (2\%). In females the cervial cancers had the highest frequency 253 (22\%), followed by the breast 224 (19\%), thyroid 157 (13.0 $\%$ ), oral cavity and oropharynx 156 (13\%), colon and rectum 58 (5\%), stomach43 (4\%), gallbladder 26 (2\%), ampullary region $22(2 \%)$, urinary bladder $16(01 \%)$, oesophagus $16(01 \%)$. Conclusion: Bangladesh is still lacking an effective national cancer registry. With a cancer load of more than one million, a cancer registry is an urgent need.

Keywords: Pathological Findings, Malignant, Tumor, Histopathology, Cytopathology.

Copyright @ 2020: This is an open-access article distributed under the terms of the Creative Commons Attribution license which permits unrestricted use, distribution, and reproduction in any medium for non-commercial use (NonCommercial, or CC-BY-NC) provided the original author and source are credited.

\section{INTRODUCTION}

Cancer is a major health challenge all over the world. It has devastating effect on individual, family and society. The number of cancer deaths worldwide has been considered to be about 4 million each year. An estimated 12.66 million people were diagnosed with cancer across the world in 2008, and 7.56 million 
people died from the disease. During the past century, cancer has emerged as the most challenging problems for public health systems in medium- and low-resource countries. At present, half of the new cancer cases in the world occur in the developing countries. Bangladesh is not spared from this problem. According to Bangladesh Bureau of Statistics cancer is the sixth leading cause of death in Bangladesh (BBS, 2008). One of the first steps in controlling the cancer burden is to collect information about the incidence, type, location of cancer etc. This is best done through "Cancer Registry [1]". To control cancer proper recording of data on cancer is essential. Data such as death certificates and hospital statistics are not sufficient alone for the analysis of the cancer incidences and monitoring of the patterns. The synonym 'tumor registry' is often used particularly in the United States of America [2]. This term appears more appropriate, because most cancer registries include the registration of a number of benign and malignant tumors. Moreover, ICD code which is used in cancer registry also includes benign tumors. Bangladesh has not yet initiated a national population based cancer registry. Cancer load is more than $1,200,000$ in Bangladesh. According to Bangladesh Bureau of Statistics cancer is the sixth leading cause of death in Bangladesh (BBS, 2008). Each year more than 200,000 people develop cancer and 150,000 die of the disease. IARC estimated death from cancer in Bangladesh was $7.5 \%$ in 2005 and will be increased up to $13 \%$ in 2030. Maintenance of a file or register of all cancer cases in a defined population is called cancer registry. The other name commonly used is tumor registry. Tumor registries are systems for collection, storage, analysis and interpretation of data from people with cancer [3]. It involves recording of personal particulars of cancer patients and the clinical and pathological characteristics of the cancers, collected continuously and systematically from various data sources [2]. To control cancer proper data on cancer trend is essential. Cancer registry is the tool which can provide such information. One of the critical steps in controlling the cancer burden is to collect information about the incidence, type, and location of cancers. This is best done within the framework of cancer registries [4]. Main target of a cancer registry is to record information from all cancer cases to produce statistics on the cancer prevalence in a given population. Cancer registry in developing countries often starts on the basis of cases attending hospitals, or of cases of cancer diagnosed in a department of histopathology. The number of people developing cancer is expected to increase in number mainly because of ageing population, lifestyle factors and access to health facilities. A population-based cancer registry is usually easier to achieve in smaller countries with good infrastructure. Though it is ideal, may not be practicable in developing countries due to restrictions of finances and a lack of technical expertise. Therefore, most developing countries lack a well-organized cancer control program largely due to a deficiency of incidence data. Pathology-based cancer data is a high quality reflection of the patterns of cancer in the population it represents, provided the demographic details of the patients are carefully recorded. A good quality, largescale pathology data with demographic details of the patient can give coverage to the population [3]. As integral part of tumor reporting, all the pathology centers keep some basic information in Bangladesh. For a successful hospital based tumor registry a wellequipped medical record department with skilled manpower record system is needed. This infrastructure is poorly developed in most of the hospitals, so hospital- based tumor registry is difficult to implement at present.

\section{Methodology and Materials}

This is a cross sectional study conducted at the Department of Pathology, Bangabandhu Sheikh Mujib Medical University, Dhaka from October 2011 to September 2012. The study had two parts: 1 . Establishment of pathology based tumor registry (PBTR) at BSMMU; 2. Analysis of data gathered during the study period. All tumor cases diagnosed by histopathology or cytopathology in the department of Pathology, BSMMU were enrolled in this study. About 12,000 histopathology specimens are received each year. Similarly, many patients come for cytopathology. It is therefore a very suitable place to start a pathology based tumor registry. With this aim, pathology department started planning a registry. The BSMMU administrative authority encouraged the move. The materials for diagnoses were biopsy specimens, surgical resection/excised specimens, and cytology specimens. The adult and paediatrics haematology departments of BSMMU are under separate administration and pulmonology is in its developing phase. Therefore, hematological malignancy and lung cancer cases were not included at this phase. Suspicious cases of tumor cases of tumor not diagnosed by histopathology or cytopathology were also not included. All tumor reports were stored in computer data base and would be retrieved according to need. Information was collected from the patients or close relatives of the patients. They were explained about tumor registry and a verbal consent was taken from the patient/ patient's guardian to be included in the study. Personal identification data and tumor related information including ICD-O3 and ICD 10 were collected and recorded systematically in a data abstraction sheet. Tumor identification part was filled up by a resident doctor. All precautions were maintained to avoid multiple counts of same patient. Data collected methodically and meticulously from October 2011 to September 2012 as far as questionnaire. These data were entered in to software by using Microsoft access. With the help of this software a master database was developed. Then data were categorized according to age group, gender, anatomical sites, benign or malignant tumor, occupation, risk behavior, socioeconomic condition and tumor identification. Sub set of data such as religion, 
geographical subdivision, rural and urban areas, etc were categorized. Basic frequency distribution and proportion of data were presented in tables, figures and diagrams. Statistical analyses of the results will be obtained by using window based computer software devised with Statistical Packages for Social Sciences (SPSS-15).

\section{RESULTS}

Among 3657 cases, 2559 were malignant (69.98\%), 1098 (30.02\%0) were benign. Among malignant tumors, $11(0.43 \%)$ cases were of low malignant potential, $17(0.66 \%)$ were borderline malignancy, $28(1.09 \%)$ cases included carcinoma insitu or intraepithelial/noninvasive malignancy, 58 $(2.27 \%)$ were uncertain whether benign or malignant, $2034(79.48 \%)$ cases were primary malignant tumors and $404(15.79 \%)$ were secondary malignant tumors (Table I). Of the total cases, $1549(42.36 \%)$ were male and $2108(57.64 \%)$ were female. The male: female ratio was 1: 1.36. In 2034 malignant tumor cases, were divided into age group decades. The age range was from 2 to 85 years. Considering each decade, fifth decade contained highest number of cases followed by sixth and fourth decade. The age range was from 2 to 85 years mean $47.30 \pm 16.37$ with a range of $2-85$ years. Where the cases were divided into pediatric group $(\leq 15$ years) and adult group ( $>15$ years) among 2034 cancer patients, $1974(97.05 \%)$ patients were in adult group, 60 $(2.85 \%)$ in the pediatric group. Table 4.2.2 showed Sarcoma $16(26.66 \%)$ was the most frequent malignant tumor in pediatrics age group followed by nephroblastoma $8(13.33 \%)$. neuroblastoma $5(8.33 \%)$. Distribution according to nature of procedure shows, 1482 (38\%) biopsy cases, 857 (24.3\%) resected specimens, $1281(36.0 \%)$ FNAC cases, 34 (1.0\%) cytology samples of body fluid cases and $3(0.1 \%)$ Scrapping / brushing cases (Table IV). Oral cavity and oropharynx represented the highest number of cases i.e. $315(15.49 \%)$, followed by cervix $253(12.44 \%)$ breast $224(11.01 \%)$, thyroid $214(10.52 \%)$, stomach 126 $(6.19 \%)$, colon and rectam $117(5.75 \%)$, Liver $77(3.79 \%)$, Urinary bladder 72 (3.54\%), Ampulla region 67 (3.29\%) and Kidney 48 (2.36\%) (Table V). Ranking of Male Malignant Tumors shown in Table VI describes, in male, oral cavity and oropharynx cancer top the list $159(18 \%)$, followed by the stomach 83 $(10 \%)$, liver $63(7.0 \%)$, colon and rectum $59(7 \%)$ urinary bladder $56(6.0 \%)$, thyroid $57(7.0 \%)$, lymph node $21(2 \%)$, kidney $33(4.0 \%)$, peri-ampullary carcinoma $45(5.0 \%)$ and oesophagus 19 (2\%). Table VII showed ranking of female malignancies in different sites. In females the cervial cancers had the highest frequency $253(22 \%)$, followed by the breast 224 $(19 \%)$, thyroid $157(13.0 \%)$, oral cavity and oropharynx $156(13 \%)$, colon and rectum $58(5 \%)$, stomach43 $(4 \%)$, gallbladder $26(2 \%)$, ampullary region $22(2 \%)$, urinary bladder $16(01 \%)$, oesophagus 16 $(01 \%)$. Table VIII shows histopathological diagnosis of malignant tumorin patients. Among 2034 malignant cases, diagnosis is squamous cell carcinoma in 722 $(35.49 \%)$ cases, adenocarcinoma in $360(17.70 \%)$ cases, ductal carcinoma of breast in $222(10.91 \%)$ cases, papillary carcinoma of thyroid in $189(9.29 \%)$ cases, hepatocellular carcinoma $67(3.29 \%)$ cases, urothelial carcinoma $61(03 \%)$ cases, lymphoma 32 (1.57\%) cases. Table IX showed frequency of different sites of malignant tumors in oral cavity. Buccal mucosa represents the highest figure $99(31.42 \%)$ followed by tongue $56(17.77 \%)$, check $30(9.52 \%)$, and palate 27 $(8.57 \%)$, tonsillar region $24(7.61 \%)$ and alveolar region 23 (7.30\%). Among 1098 benign tumors, lipoma ranked the first $392(35.70 \%)$ followed by fibroadenoma $276(25.16 \%)$, pleomorphic adenoma 89 $(8.10 \%)$, leiomyoma $53(4.82 \%)$ and schwannoma $48(4.37 \%)$.

Table-I: Distribution of patients according to tumor behavior

\begin{tabular}{|c|c|c|}
\hline Tumor behavior & Frequency & Percentage \\
\hline Benign & 1098 & 30.02 \\
\hline Malignant & 2559 & 69.98 \\
\hline $\begin{array}{c}\text { Uncertain whether benign or } \\
\text { malignant }\end{array}$ & 58 & 1.58 \\
\hline Borderline malignancy & 17 & 0.47 \\
\hline Low malignant potential & 11 & 0.30 \\
\hline Carcinom in-situ & 28 & 0.76 \\
\hline Malignant, primary site & 2034 & 55.62 \\
\hline Malignant, secondary site & 404 & 11.05 \\
\hline Total & $\mathbf{3 6 5 7}$ & $\mathbf{1 0 0 . 0}$ \\
\hline
\end{tabular}




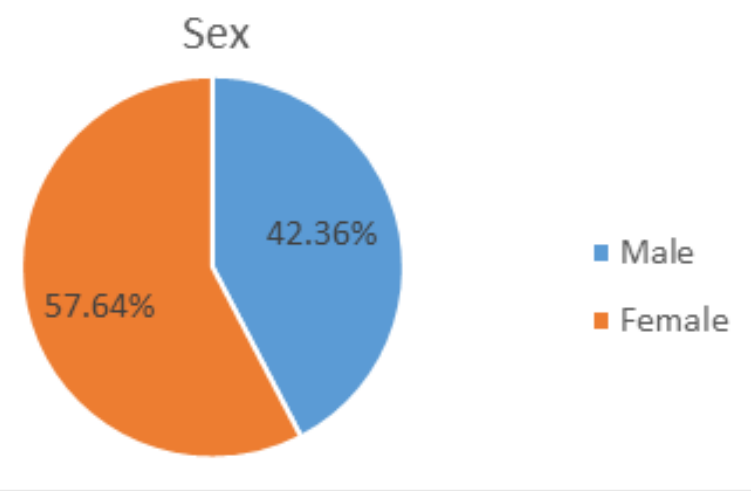

Fig-I: Sex distribution of patients

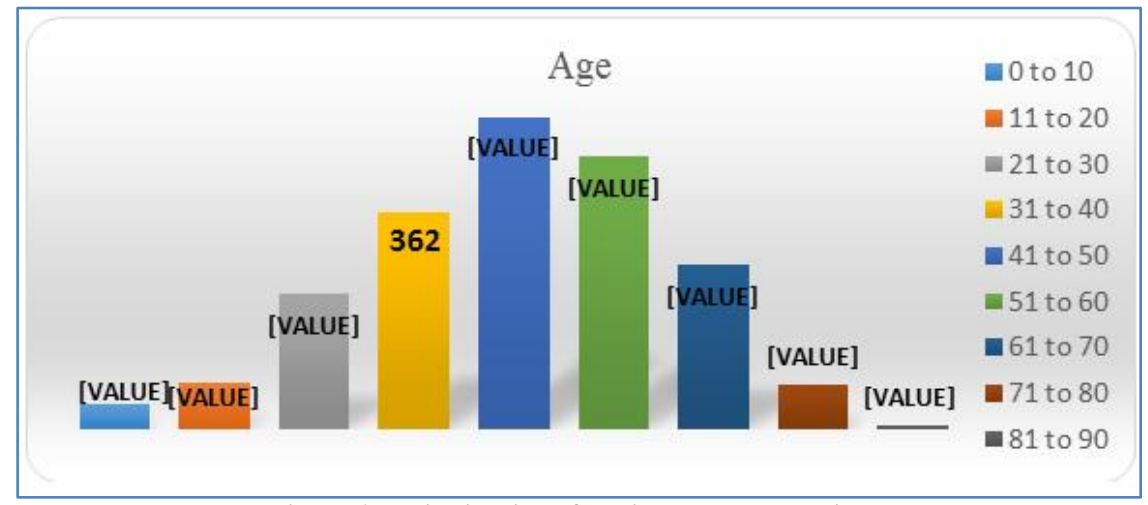

Fig-II: Age distribution of malignant tumor patients

Table-II: Distribution of malignant tumor according to age group

\begin{tabular}{|l|r|r|r|}
\hline \multicolumn{2}{|l|}{ Age group } & \multicolumn{1}{c|}{ Frequency } & Percentage \\
\hline Pediatric & $<15$ & 60 & 2.95 \\
\hline Adult & $15>$ & 1974 & 97.05 \\
\hline \multicolumn{2}{|c|}{ Total } & 2034 & 100.00 \\
\hline
\end{tabular}

Table-III: Ranking of paediatric ( $<15$ years) malignant tumors

\begin{tabular}{|c|c|c|}
\hline Site & Frequency & Percentage \\
\hline Sarcoma & 16 & 26.66 \\
\hline Nephroblastoma & 08 & 13.33 \\
\hline Neuroblastoma & 05 & 8.33 \\
\hline Papillary carcinoma of thyroid & 05 & 8.33 \\
\hline Hepatoblastoma & 04 & 6.66 \\
\hline Medulloblatoma & 04 & 6.66 \\
\hline Non Hodgkin lymphoma & 04 & 6.66 \\
\hline Others & 14 & 23.33 \\
\hline Total & $\mathbf{6 0}$ & $\mathbf{1 0 0 . 0}$ \\
\hline
\end{tabular}

Table IV: Distribution according to nature of procedure

\begin{tabular}{|c|c|c|c|}
\hline & Procedure & Frequency & Percentage \\
\hline Histopathology & Biopsy & 1482 & 38.0 \\
\cline { 2 - 4 } & Resection & 857 & 24.3 \\
\hline Cytopathology & FNAC & 1281 & 36 \\
\cline { 2 - 4 } & Cytology of body fluid & 34 & 1.0 \\
\cline { 2 - 4 } & Scrapping / Brushing & 3 & 0.1 \\
\hline Total & \multicolumn{3}{|c}{} \\
\hline
\end{tabular}


Table-V: Distribution of malignant tumors according to site

\begin{tabular}{|c|c|c|}
\hline Site & Frequency & Percentage \\
\hline Oral cavity and oropharynx & 315 & 15.49 \\
\hline Cervix & 253 & 12.44 \\
\hline Breast & 224 & 11.01 \\
\hline Thyroid & 214 & 10.52 \\
\hline Stomach & 126 & 6.19 \\
\hline Colon and Rectum & 117 & 5.75 \\
\hline Liver & 77 & 3.79 \\
\hline Urinary bladder & 72 & 3.54 \\
\hline Ampullary region & 67 & 3.29 \\
\hline Kidney & 48 & 2.36 \\
\hline Others & 521 & 25.61 \\
\hline Total & 2034 & 100.00 \\
\hline
\end{tabular}

Table-VI: Ranking of Male Malignant Tumors

\begin{tabular}{|c|c|c|}
\hline Site & Frequency & Percentage \\
\hline Oral cavity and oropharynx & 159 & 18 \\
\hline Stomach & 83 & 10 \\
\hline Liver & 63 & 7 \\
\hline Colon and Rectum & 59 & 7 \\
\hline Thyroid & 57 & 7 \\
\hline Urinary bladder & 56 & 6 \\
\hline Ampulla region & 45 & 5 \\
\hline Kidney & 33 & 4 \\
\hline Lymph node & 21 & 2 \\
\hline Oesophagus & 19 & 2 \\
\hline Others & 274 & 32 \\
\hline Total & 869 & 100.00 \\
\hline
\end{tabular}

Table-VII: Ranking of Female Malignant Tumors

\begin{tabular}{|c|c|c|}
\hline Site & Frequency & Percentage \\
\hline Cervix & 253 & 22 \\
\hline Breast & 224 & 19 \\
\hline Thyroid & 157 & 13 \\
\hline Oral cavity and oropharynx & 156 & 13 \\
\hline Colon and Rectum & 58 & 5 \\
\hline Stomach & 43 & 4 \\
\hline Gallbladder & 26 & 2 \\
\hline Ampullary region & 22 & 2 \\
\hline Urinary bladder & 16 & 1 \\
\hline Oesophagus & 16 & 1 \\
\hline others & 194 & 17 \\
\hline Total & 1165 & 100 \\
\hline
\end{tabular}

Table-VIII: Distribution of malignant tumor according to diagnosis

\begin{tabular}{|c|c|c|}
\hline Diagnosis & Frequency & Percentage \\
\hline Squamous cell carcinoma & 722 & 35.49 \\
\hline Adenocarcinoma & 360 & 17.70 \\
\hline Duct cell carcinoma & 222 & 10.91 \\
\hline Papillary carcinoma & 189 & 9.29 \\
\hline Hepatocellular carcinoma & 67 & 3.29 \\
\hline Urothelial transitional cell carcinoma & 61 & 3.00 \\
\hline Lymphoma & 32 & 1.57 \\
\hline Other & 381 & 18.73 \\
\hline Total & 2034 & 100.00 \\
\hline
\end{tabular}


Table-IX: Distribution of malignant tumor in different site of oral cavity

\begin{tabular}{|c|c|c|}
\hline Site & Frequency & Percentage \\
\hline Buccal mucosa & 99 & 31.42 \\
\hline Tongue & 56 & 17.77 \\
\hline Cheek & 30 & 9.52 \\
\hline Palate & 27 & 8.57 \\
\hline Tonsillar region & 24 & 7.61 \\
\hline Alveolar region & 23 & 7.30 \\
\hline Pyriform fossa & 19 & 6.03 \\
\hline Base of the tongue & 12 & 3.80 \\
\hline Posterior pharyngeal & 11 & 3.49 \\
\hline wall & & \\
\hline Vestibular area & 7 & 2.22 \\
\hline Retro molar area & 7 & 2.22 \\
\hline Total & $\mathbf{3 1 5}$ & $\mathbf{1 0 0 . 0}$ \\
\hline
\end{tabular}

Table-X: Distribution of benign tumor

\begin{tabular}{|c|c|c|}
\hline Benign tumor & Frequency & Percentage \\
\hline Lipoma & 392 & 35.70 \\
\hline Fibroadenoma & 276 & 25.13 \\
\hline Pleomorphic adenoma & 89 & 8.10 \\
\hline Leiomyoma & 53 & 4.82 \\
\hline Haemangioma & 51 & 4.64 \\
\hline Schwanoma & 48 & 4.37 \\
\hline Meningioma & 33 & 3.00 \\
\hline Neurofibroma & 17 & 1.54 \\
\hline Other & 139 & 12.65 \\
\hline Total & $\mathbf{1 0 9 8}$ & $\mathbf{1 0 0}$ \\
\hline
\end{tabular}

\section{DISCUSSION}

The first part of the pilot project was to establish a pathology based tumor registry at BSMMU hence to assess and define the problems and pitfalls encountered during establishing the registry. With collaboration from the University of Chicago under the existing memorandum of understanding with BSMMU, a pathology based tumor registry started at the Department of Pathology, BSMMU in October 2011. A well-equipped room within the Pathology department had been allocated for this purpose and named "Tumor Registry Cell" which was officially inaugurated by the Vice Chancellor of BSMMU. A valid and reliable questionnaire and software for data entry were developed with the help of the University of Chicago, USA. MacLennan [2] method of questionnaire was followed. It has two parts. The first part is a questionnaire designed to record the demographic details of a tumor bearing patient including name, identification particulars, risk behaviors, socioeconomic status, occupation, family history of cancer etc. The second part is to record the pathological diagnosis of tumor including its topography, mode of diagnosis, type and grade of tumor with its ICD-O code etc. A Bengali version of the questionnaire was also developed for better understanding of the responders. The information collected was entered into the database by software Microsoft Access 2003 and Visual Basic 6. Some difficulties had been faced during setting up of the tumor registry. Preparation of the questionnaire and development of software for database were difficult task and needed expertise which was provided by the University of Chicago Research Bangladesh, a Dhakabased research center affiliated with the University of Chicago, USA. As there was no trained staff to work for the registry, the investigator himself had to collect the data including demographic details from the patients or their attendants. Some of the patients were unenthusiastic to fill up the questionnaire while some were illiterate. The investigator had to motivate them to fill up the questionnaire or when illiterate, had to fill up the form himself by interviewing the questions one by one. The data were mainly based on histopathology or cytopathology diagnosis of tumors excluding lung and hematological malignancies. Because the latter cases were diagnosed in the department of hematology, so only a few trephine biopsy samples of bone marrow were available. The thoracic surgery and respiratory medicine departments started a few years ago and had only few cases. For this reason, lung samples were scarce. The study included only the cases of tumors that were diagnosed in the department of pathology, BSMMU from October 2011, to September, 2012. A total of 3657 tumor cases, including both benign and malignant tumors, could be enrolled for the final analysis. Data were analyzed in two groups based on complete and partly incomplete information. The first one was data collected from 3657 tumor cases contained both complete and incomplete data and the second one was 1135 tumor cases contained only complete data. Data from 2522 cases were partly incomplete due to failure to communicate with the tumor bearing patients. The information taken were age, sex, religion, marital status, area, occupation, socioeconomic condition, risk behavior, family history, co morbidity, site, morphologic diagnosis, grade, stage, primary or metastatic. The distribution of benign and malignant tumors in the study showed predominance of malignant tumors constituting a majority of $69.98 \%$. The reasons may be as follows: i) some of the benign tumors were not sent for histopathological examination; ii) as BSMMU is a tertiary care hospital, it receives mostly the difficult cases and also the referred cases from various regions of the country. The age range of the patients was from 2 to 85 years with a mean age of $47.30 \pm 16.37$ years. According to IARC, the median age for individual countries ranges from around 45 years (for example, in Japan and Germany). The National Cancer Control Strategy and Plan of Action for 2009-2015 of Bangladesh have stated that more than $66 \%$ of the cancers occur in the age group of 30-65 years. Talukder et al. [5] showed that peak incidence of malignant tumors was more common in the fourth decade. The present study showed that the frequency of malignant tumor was more from fourth decade to sixth decade. Frequency of the pediatric tumors was $2.85 \%$. The National Cancer Control Strategy and Plan of Action for 2009-2015 of Bangladesh stated that children 
with cancer represented 1 percent of the overall incidence of the disease. NICRH found that in children aged 14 years or younger, lymphoma, retinoblastoma, osteosarcoma, leukemia and kidney tumors were most commonly found. Korir and Mutuma ${ }^{6}$ showed that retinoblastoma had the highest frequency. In this study, sarcoma was the most common tumor in pediatric age group followed by nephroblastoma.

Male to female ratio in the study population was 1: 1.36. Similar findings were found by some studies [5-7]. But IARC and cancer research, UK 2009 jointly showed that only four cancer sites - lung (13\%), female breast $(11 \%)$, colorectum $(10 \%)$ and stomach $(08 \%)$ accounted for two-fifths (41\%) of the world's total. Lung cancer has been estimated as the most common cancer in the world for several decades. An estimated 1.61 million people across the world were diagnosed with lung cancer in 2008, accounting for $13 \%$ of the total, more than half $(55 \%)$ of the cases occurred in the developing world. In the present study, oral cavity and oropharynx cancers represented the highest frequency $(15.49 \%)$ followed by cervix (12.44\%), breast $(11.01 \%)$, thyroid $(10.52 \%)$, stomach $(6.19 \%)$, colorectal $(5.75 \%)$, liver $(3.79 \%)$ Lung specimen is not available at this institution, because thoracic surgery department is in its preliminary stage.

\section{Limitations OF THE STUdy}

Like any other scientific studies this study has some limitations which needs to clarify. Firstly, Hematological malignancy is not included in this study. Because it is a separate department. Therefore, a percentage of malignant cases are excluded. Secondly, due to unavailability of lung specimen, a major cancer of male patients in Bangladesh could not be included in this study. And finally, in large number of cases, complete data could not be recorded because of lack of awareness within the population, limited manpower and lack of experience.

\section{CONCLUSION AND \\ RECOMMENDATIONS}

Bangladesh is still lacking an effective national cancer registry. With a cancer load of more than one million, a cancer registry is an urgent need. Establishment of cancer registry faces certain challenges, such as, deficiency of basic health services, lack of demographic data, lack of trained staff, lack of patient monitoring, lack of devices and tools, financial problems and failure to achieve institutionalization. Despite all these constraints, the aim will be, to develop a hospital- or pathology-based registry at least in the beginning, though a National Population based cancer registry should be the ultimate goal. Through this research project a pathology based cancer registry cell will be established at BSMMU. It will be supported by technical help from the Department of Health Studies (Epidemiology), Medicine and Human Genetics, University of Chicago through the existing Memorandum of Understanding. The tumor registry will be continued phase wise. The experience gained during this will help expansion of cancer registry with phase wise incorporation of other institutes throughout the country. Data generated from this cancer registry will then help formulation of strategies to prevent and control cancer in Bangladesh.

\section{REFERENCES}

1. Etemadi A, Alireza S, Shahryar S, Seyed MN, Hooman K and Moslem B. Cancer Registry in Iran: A Brief Overview. Arch Iranian Med.2008; 11(5): 577-580.

2. Jensen OM and Whelan S. Planning a Cancer Registry, in Jensen OM Parkin DM, MacLennan R, Muir CS, and Skeet RG (eds). Cancer Registration: Principle and Method Lyon: IARC publ; 1991.

3. Bhurgri Y, Hasan SH, Pervez S, Kayani N, Hussainy AS, Muzaffar S and Khurshid $M$. Large-scale pathology-based cancer data a reflection of population-based cancer data. Pathol Oncol Res.2002; 8: 62-7.

4. Parkin DM. The evolution of the populationbased cancer registry. Nat Rev Cancer.2006; 6:603-12.

5. Talukder SI, Das RK, Chowdhury SA, Rahman MT, Begum J, Nahar M. and Ali, MY. Histopathology Based Disease Patterns in Dinajpur. Dinajpur Med Col J. 2009; 2: 13-16.

6. Mutuma G, Korir A Cancer Registry Report (2000-2002), Nairobi, 2006. Available at https:// www.healthresearchweb.org/files/CancerInciden ceReportKEMRI.pdf

7. Mokhtar $\mathrm{N}$ and Adel I. Cancer Pathology Registry 2003-2004 and Time Trend Analysis. Department of Pathology, National Cancer Institute, University of Cairo; 2007.

8. Cancer World. Retrieved February 14, 2013, from http://publications.cancerresearchuk.org; 18

9. Cancer in Queensland: Incidence, Mortality, Survival and Prevalence 1982 to 2008. Statistical Tables Queensland Cancer Registry Cancer Council Queensland. (C) The State of Queensland, Queensland Health. 2011; 4-58

10. Cancer Epidemiology in South Asia - Past, Present and Future. Asian Pacific Journal of Cancer Prevention; 10 (Asian Epidemiology Supplement). 2011: 49-67. 